\title{
The effect of ionizing radiation on properties of fluoride-releasing restorative materials
}

\section{Muhittin UGURLU(a) \\ Emine Elif OZKAN(b) iD \\ Alper OZSEVEN ${ }^{(b)}$}

\footnotetext{
(a)Süleyman Demirel University, Faculty of Dentistry, Department of Restorative Dentistry, Isparta, Turkey.

(b)Süleyman Demirel University, Faculty of Medicine, Department of Radiation Oncology, Isparta, Turkey.
}

Declaration of Interests: The authors certify that they have no commercial or associative interest that represents a conflict of interest in connection with the manuscript.

\section{Corresponding Author:}

Muhittin Uğurlu

E-mail:dtmuhittinugurlu@gmail.com

https://doi.org/10.1590/1807-3107bor-2020.vol34.0005

Submitted: March 14, 2019

Accepted for publication: December 23, 2019

Last revision: January 8, 2020

\begin{abstract}
The purpose of this study was to evaluate the effect of ionizing radiation from high energy $\mathrm{X}$-ray on fluoride release, surface roughness, flexural strength, and surface chemical composition of the materials. The study groups comprised five different restorative materials: Beautifil II, GCP Glass Fill, Amalgomer CR, Zirconomer, and Fuji IX GP. Twenty disk-shaped specimens $(8 \times 2 \mathrm{~mm})$ for fluoride release and 20 bar-shaped specimens $(25 \times 2 \times 2 \mathrm{~mm})$ for flexural strength were prepared from each material. Each material group was divided into two subgroups: irradiated (IR) and non-irradiated (Non-IR). The specimens from IR groups were irradiated with 1.8 Gy/day for 39 days (total IR = 70.2 Gy). The amount of fluoride released into deionized water was measured using a fluoride ion-selective electrode and ion analyzer after 24 hours and on days 2, 3, $7,15,21,28,35$, and $39(n=10)$. The flexural strength was evaluated using the three-point bending test $(n=10)$. After the period of measurement of fluoride release, seven specimens $(n=7)$ from each group were randomly selected to evaluate surface roughness using AFM and one specimen was randomly selected for the SEM and EDS analyses. Data were analyzed with two-way ANOVA and Tukey tests $(p=0.05)$. The irradiation significantly increased fluoride release and surface roughness for Amalgomer CR and Zirconomer groups $(p<0.05)$. No significant change in flexural strength of the materials was observed after irradiation ( $p>0.05)$. The ionizing radiation altered the amount of fluoride release and surface roughness of only Amalgomer CR and Zirconomer. The effect could be related to the chemical compositions of materials.
\end{abstract}

Keywords: Microscopy, Atomic Force; Spectrometry, X-Ray Emission; Flexural strength; Glass Ionomer Cement; Radiotherapy.

\section{Introduction}

Nowadays, most of the patients with head and neck cancer receive radiotherapy, either exclusively or together with other therapeutic methods such as surgery and chemotherapy., ${ }^{1,2}$ The ionizing radiation is used to destroy tumor cells during radiotherapy, ${ }^{3}$ but it can damage normal tissues located in the field of radiation and cause complications in the oral cavity including mucositis, xerostomia, candidiasis, osteoradionecrosis, and radiation caries. ${ }^{1,4}$ Radiation caries is one of the most common side-effects of radiotherapy in the head and neck region..$^{5,6,7}$ The ionizing radiation 
also causes permanent changes in the salivary glands, causing hyposalivation, ${ }^{1}$ and affects the organic and inorganic substrate of the teeth; hence the teeth can be more susceptible to demineralization. ${ }^{8,9,10}$

Although composite resins are the most frequently used dental restorative materials, it has been stated that glass ionomer cements (GICs) provide better protection against caries lesions associated with restorations than composite resins in irradiated patients. ${ }^{11,12}$ GICs was associated with protection against caries through the release of fluoride in irradiated patients. ${ }^{5,6,11}$ Another study concluded that recurrent caries did not develop in patients who routinely used topical fluoride gel and that the fluoride-releasing restorative materials may reduce caries surrounding restorations in these high-risk patients who do not routinely use topical fluoride. ${ }^{12}$ On the other hand, the GICs have certain drawbacks, such as early water sensitivity and low mechanical strengths; therefore, the use of GICs as direct restorative materials in stress-bearing areas is contraindicated. ${ }^{13,14}$ Several studies have been done to overcome the disadvantage of low mechanical properties. As a result, high viscosity GIC, ceramic reinforced GIC, zirconia reinforced GIC, and calcium fluorapatite nanocrystals-reinforced GIC (Glass carbomer) have been developed..$^{15,16,17}$ One of the recent developments in the fluoride-releasing restorative materials has been the introduction of the giomer materials. Giomer is a hybridized material of GIC and composite resin, containing surface pre-reacted glass ionomer (S-PRG) filler particles within a resin matrix. ${ }^{13,18}$

Furthermore, it has been stated that ionizing radiation could affect the properties of restorative materials. ${ }^{7,10}$ The effects of ionizing radiation on properties of restorative materials as surface roughness ${ }^{19,20}$, flexural strength ${ }^{19,21,22}$, microhardness, ${ }^{19,20,22}$ and water sorption ${ }^{23}$ have been evaluated in several studies. It has been concluded that ionizing radiation altered surface roughness and flexural strength, mainly of GICs. ${ }^{19}$ But the effects on the new fluoride releasing materials are not completely known. Moreover, to the best of our knowledge, no information is available in the literature regarding the effect of ionizing radiation on the fluoride release of restorative materials.
Fluoride releasing materials can prevent caries formation under restorations due to the different properties of fluoride, such as suppressing demineralization, enhancing remineralization, and interacting with many metabolic processes of bacteria. ${ }^{11,12,24}$ However, when selecting a material to restore teeth, one of the main considerations is also the mechanical properties of the material. The flexural strength test is commonly used to evaluate the mechanical properties of materials in laboratory conditions. ${ }^{25}$ Besides, the increased surface roughness might cause a decrease in mechanical properties of the materials and be a predisposing factor to microbial colonization. ${ }^{24,26}$ Therefore, the objective of this study was to evaluate the effect of ionizing radiation from high energy $\mathrm{X}$-ray on the properties of fluoride releasing restorative materials by assessing fluoride release, surface roughness, flexural strength, and chemical compositions of the materials' surface. The null hypothesis of this study was that ionizing radiation from high energy $\mathrm{X}$-ray has no significant effect on the properties of fluoride releasing restorative materials.

\section{Methodology}

Five different restorative materials were used in the present study: giomer (Beautifil II Shofu, Kyoto, Japan), glass carbomer (GCP Glass Fill, Vianen, Netherlands), ceramic reinforced GIC (Amalgomer CR Advanced Health Care Ltd, Tonbridge, UK), zirconia reinforced GIC (Zirconomer, Shofu, Kyoto, Japan), and high viscosity GIC (Fuji IX GP Capsule GC, Tokyo, Japan). The materials are listed in Table 1 together with the compositions, manufacturers, and lot numbers.

\section{Specimen preparation}

A total of 100 disk-shaped specimens, 20 samples from each restorative material, $8 \mathrm{~mm}$ in diameter and $2 \mathrm{~mm}$ thickness were prepared for the fluoride release test. A total of 100 bar-shaped specimens ( $25 \times 2 \times 2 \mathrm{~mm}), 20$ samples from each restorative material were prepared for the flexural strength test. Each material was inserted into Teflon molds and covered on both sides with Mylar strips and glass 
Table 1. Composition of the materials according to the manufacturers' data.

\begin{tabular}{|c|c|c|c|c|}
\hline Materials & Type & Composition & Manufacturer & Lot \\
\hline Beautifil II & Giomer & $\begin{array}{l}\text { BISGMA, TEGDMA, Aluminofluoro-borosilicate glass } \\
\text { filler, aluminum oxide, silica, prereacted glass ionomer } \\
\text { filler, Camphoroquinone }\end{array}$ & Shofu, Kyoto, Japan & 111787 \\
\hline GCP Glass Fill & Glass carbomer & $\begin{array}{l}\text { Fluoroaluminosilicate glass, nano } \\
\text { fluoro/hydroxyapatite, polyacids }\end{array}$ & GCP, Vianen, Netherlands & 71702144 \\
\hline \multirow[t]{2}{*}{ Amalgomer CR } & & $\begin{array}{l}\text { Powder: Fluoroaluminosilicate glass, polyacrylic acid powder, } \\
\text { tartaric acid powder, ceramic reinforcing powder. }\end{array}$ & \multirow{2}{*}{$\begin{array}{l}\text { Advanced Health Care } \\
\text { Ltd, Tonbridge, UK }\end{array}$} & \multirow[t]{2}{*}{$011804-81$} \\
\hline & Reinforced GIC & Liquid: Polyacrylic acid, distilled water & & \\
\hline Zirconomer & $\begin{array}{l}\text { Zirconia reinforced } \\
\text { GIC }\end{array}$ & $\begin{array}{l}\text { Powder: Fluoroaluminosilicate glass, zirconium oxide, pigments } \\
\text { Liquid: Polyacrylic acid solution, tartaric acid }\end{array}$ & Shofu, Kyoto, Japan & 2160281 \\
\hline Fujı IX GP & High viscosity GIC & $\begin{array}{c}\text { Polyacrylic acid, fluoroaluminosilicate glass, polybasic } \\
\text { carboxylic acid }\end{array}$ & GC, Tokyo, Japan & $180110 \mathrm{~A}$ \\
\hline
\end{tabular}

Bis-GMA: Bisphenol A diglycidyl methacrylate; TEGDMA: Triethylene glycole dimethacrylate

plates to excess material to extrude and produce a smooth surface. The giomer material was polymerized through the glass plate using a LED light curing unit (Smartlite Focus, Dentsply, Milford, USA) according to the manufacturer's instructions. The bar-shaped specimens were light activated on four contiguous surface regions, ensuring light activation to the full length of the specimen. For the glass carbomer and the high viscosity GIC, a capsule mixer (Silver Mix, Stomamed, Bratislava, Slovakia) was used to mix the material for 10 seconds before application. The ceramic reinforced GIC and zirconia reinforced GIC were mixed for 30 seconds according to the manufacturer's instructions. Immediately after light curing and setting cycle, specimens were removed from the mold. All specimens were prepared by the same operator.

\section{Fluoride release}

The specimens prepared for the fluoride release analysis were stored for 1 hour at $37^{\circ} \mathrm{C}$ and $100 \%$ humidity. Then, the specimens were finished/polished with graded series (coarse, medium, fine, and extra fine) of Super-Snap discs (Super Snap Rainbow Technique Kit, Shofu, Kyoto, Japan, Lot:0413007). Each abrasive disk was used only once for each material, in wet condition for 1 minute, using a handpiece of 10.000 revolutions per minute as recommended by the manufacturer. After each polishing step, all the specimens were thoroughly rinsed with water and air-dried to remove debris. One single operator did all of the polishing treatments, trying to simulate clinical finishing and polishing procedure. Thereafter, the specimens were randomly divided into two subgroups for each material $(n=10)$ : irradiated (IR) and non-irradiated (Non-IR) as control.

The non-irradiated specimens were immersed in a plastic container containing $5 \mathrm{~mL}$ of deionized water at $37^{\circ} \mathrm{C}$. After $24 \mathrm{~h}$, the containers were thoroughly shaken and the water was removed and analyzed. After, the specimens were re-immersed in $5 \mathrm{~mL}$ of fresh deionized water. Measurements of released fluoride were done after 24 hours and on days 2, 3, $7,15,21,28,35$, and 39. Each $5 \mathrm{~mL}$ storage water was mixed with $5 \mathrm{~mL}$ of total ionic strength adjustable buffer (TISAB II) solution and analyzed for fluoride ions with the use of an ion-specific electrode (Orion 9609BNWP, Orion Research, Chicago, USA) connected to an ion analyzer supplied with the measuring unit (Thermo Orion $720 \mathrm{~A}+$, Orion Research, Chicago, USA). The system was calibrated prior to each evaluation with fluoride standards ranging from 0.1 to $100 \mathrm{ppm}$.

The specimens from each material group $(n=10)$ were irradiated simulating a radiotherapy procedure applied to patients with head and neck cancer. Each specimen was placed into a plastic container containing $5 \mathrm{~mL}$ of deionized water and the containers were positioned in a glass beaker filled up with deionized water. The X-ray computed tomography (CT) images were obtained from the plastic containers located in the beaker by using CT scanner (Bright Speed Excel Select, General Electric Medical Systems, Fairfield, USA). 3D conformal planning technique was used as treatment delivery. Before irradiation 
of the specimens, the position of the containers and beakers were verified by using an imaging system (Portal Vision, Varian Medical System, Palo Alto, USA). Radiation was performed in a hospital environment using a linear accelerator (Varian Clinac DBX 600 system, Varian Medical System, Palo Alto, USA). The protocol recommended in previous studies was used ${ }^{2,4,17}$ : a total dose of 70.2 Gy divided in 39 daily applications of $1.8 \mathrm{~Gy}$. The treatment plan was created by the radiotherapist using the Eclipse treatment planning system (Varian Medical System, Palo Alto, USA). Anisotropic Analytical Algorithm (AAA) dose calculation algorithm was used during planning process to ensure same radiation dose to all IR specimens.

Measurements of fluoride release in the IR subgroups were also evaluated after 24 hours and on days $2,3,7,15,21,28,35$ and 39 in the same way.

\section{Surface roughness}

After the fluoride release measurement period, seven specimens $(n=7)$ from each group were randomly selected to evaluate surface roughness. Atomic force microscopy (AFM, ezAFM, NanoMagnetics Instruments, Ankara, Turkey) was used to determine the mean surface roughness values ( $\mathrm{Ra}$ ) of the specimens assessed using a $\mathrm{Si}_{3} \mathrm{~N}_{4}$ tip with frequency of $1 \mathrm{~Hz}$ in contact mode. Three different areas were randomly selected with a scan area of $5 \times 5 \mu \mathrm{m}$ and resolution of $512 \times 512$ pixels to obtain surface roughness values. The analysis of surface roughness values was done by NMI ezAFM v4.8.2.3 control software and the mean roughness value was determined for each specimen. Then, three-dimensional (3D) images were acquired for each group.

\section{SEM and EDS analysis}

After the fluoride release measurement period, one specimen from each group was randomly selected for SEM (Scanning Electron Microscopy) and EDS (Energy Dispersive X-ray Spectroscopy) analysis. All specimens were adhered with conductive carbon tape to aluminum stubs and observed under SEM (Quanta Feg 250, FEI, Netherlands) with secondary electrons at $\times 5000, \times 10000$ and $\times 20000$ magnification by $20 \mathrm{kV}$. EDS analyses were done at the same time of
SEM micrographs. An area of approximately $50 \times 40$ $\mu \mathrm{m}$ from the center of each specimen was selected for EDS analysis.

\section{Three-point flexural strength}

The bar-shaped specimens were also randomly divided into two subgroups for each material $(\mathrm{n}=10)$; irradiated (IR) and non-irradiated (Non-IR) as control. The non-IR specimens were stored in deionized water at $37^{\circ} \mathrm{C}$ until testing and the water was changed weekly up to test periods. The other specimens were irradiated into a beaker as described earlier.

The flexural strength was evaluated using the three-point bending test (ISO 4049) with a $20-\mathrm{mm}$ span at a crosshead speed of $1 \mathrm{~mm} / \mathrm{min}$ on a computer-controlled a custom-made testing machine specially designed for mechanical testing of lowstrength materials at the Mechanical Engineering Department of Suleyman Demirel University in Isparta, Turkey. The custom-made testing machine was equipped with a $100 \mathrm{~N}$ load cell (Tedea Huntleigh MN:16, Malvern, USA). Before testing, the specimen dimensions ( $25 \mathrm{~mm}$ in length, $2 \mathrm{~mm}$ in width, and $2 \mathrm{~mm}$ in thickness) were verified using a digital caliper (Digimatic Caliper, Mitutoyo, Tokyo, Japan). The flexural strength (FS) of the material was calculated by $\mathrm{FS}=3 \mathrm{P}_{\max } \mathrm{L} /\left(2 \mathrm{bh}^{2}\right)$, where $\mathrm{P}_{\max }$ is the maximum load $(\mathrm{N})$ on the load-displacement curve, $\mathrm{L}$ is the span length $(\mathrm{mm}), \mathrm{b}$ is the width of the specimen $(\mathrm{mm})$, and $\mathrm{h}$ is the thickness of the specimen (mm).

\section{Statistical analysis}

Statistical analyses were performed with the SPSS Program, version 20.0 (Statistical Package for the Social Sciences; SPSS, Chicago, USA). The Kolmogorov-Smirnov test was applied to verify if the data were normally distributed, and the data were found to have a normal distribution. The data were also statistically homogenous. The data of fluoride release were analyzed using two-way repeated analysis of variance (ANOVA) and the other data were analyzed using two-way ANOVA, followed by post-hoc Tukey's tests to compare the means between groups. The p-value less than 0.05 was considered statistically significant for all statistical analyses. The correlation between the properties of the materials 
(fluoride release, surface roughness, and flexural strength) were evaluated with Pearson's correlation.

\section{Results}

The mean and standard deviations of the amount of fluoride release for each subgroup in all the material groups were recorded in ppm on all the measurement days and presented in Table 2. For all subgroups, the greatest amount of fluoride release occurred after $24 \mathrm{~h}$. Fluoride release decreased with time, but continued throughout the entire 39-day test period. After $24 \mathrm{~h}$, the lowest fluoride release was observed in Beautifil II groups and the highest fluoride release was observed in Zirconomer groups ( $\mathrm{p}<0.05)$. The ionizing radiation significantly increased the amount of fluoride released from Zirconomer during all measurement days except $39^{\text {th }}$ day while it increased the amount of fluoride released from Amalgomer CR at the $1^{\text {st }}, 2^{\text {nd }}, 3^{\text {rd }}, 7^{\text {th }}$, and $28^{\text {th }}$ days $(\mathrm{p}<0.05)$. However, the ionizing radiation did not affect the amount of fluoride released from Beautifil II, GCP Glass Fill, and Fuji IX GP ( $p>0.05)$.

The surface roughness values $(\eta \mathrm{m})$ of the materials in the Non-IR and IR subgroups are indicated in Table 3. The irradiation significantly increased Ra values of only Amalgomer CR and Zirconomer groups $(\mathrm{p}<0.05)$. The highest Ra values was observed

Table 2. Mean and standard deviation values of the amounts of fluoride release (ppm) for each material and subgroup (Non-IR; non-irradiated, IR; irradiated) during the 39-day period.

\begin{tabular}{|c|c|c|c|c|c|c|c|}
\hline Variable & & Beautifil II & GCP Glass Fill & Amalgomer CR & Zirconomer & Füı IX GP & $\mathrm{p}^{\ddagger}$ \\
\hline \multirow{3}{*}{ Day 1} & Non-IR & $1.45 \pm 0.32^{a}$ & $13.84 \pm 2.03^{b}$ & $19.83 \pm 2.04^{c}$ & $25.20 \pm 2.21^{d}$ & $15.74 \pm 1.42^{b}$ & 0.000 \\
\hline & $\mathbb{I R}$ & $1.44 \pm 0.30^{\circ}$ & $14.04 \pm 1.97^{b}$ & $25.13 \pm 2.19 c$ & $29.31 \pm 2.45^{d}$ & $15.70 \pm 1.39^{b}$ & 0.000 \\
\hline & ${ }^{p} \dagger$ & 1.000 & 1.000 & 0.000 & 0.000 & 1.000 & \\
\hline \multirow{3}{*}{ Day 2} & Non-IR & $1.21 \pm 0.19^{a}$ & $10.94 \pm 1.86^{b}$ & $13.84 \pm 1.74^{c}$ & $20.02 \pm 1.56^{d}$ & $11.04 \pm 1.75^{b}$ & 0.000 \\
\hline & $\mathbb{R}$ & $1.21 \pm 0.17^{a}$ & $11.04 \pm 1.75^{b}$ & $19.82 \pm 2.04^{c}$ & $25.14 \pm 2.26^{d}$ & $11.02 \pm 1.76^{b}$ & 0.000 \\
\hline & $\mathrm{p}^{\dagger}$ & 1.000 & 1.000 & 0.000 & 0.000 & 1.000 & \\
\hline \multirow{3}{*}{ Day 3} & Non-IR & $1.04 \pm 0.29^{a}$ & $8.01 \pm 1.02^{b}$ & $8.07 \pm 1.07^{b}$ & $14.94 \pm 1.40^{c}$ & $8.47 \pm 0.78^{b}$ & 0.000 \\
\hline & $\mathbb{R}$ & $1.05 \pm 0.27^{\circ}$ & $8.05 \pm 1.05^{b}$ & $13.86 \pm 1.73^{c}$ & $20.01 \pm 1.56^{d}$ & $8.45 \pm 0.77^{b}$ & 0.000 \\
\hline & $\mathrm{p}^{\dagger}$ & 1.000 & 1.000 & 0.000 & 0.000 & 1.000 & \\
\hline \multirow{3}{*}{ Day 7} & Non-IR & $0.81 \pm 0.08^{a}$ & $6.94 \pm 0.49^{b}$ & $5.88 \pm 0.56^{c}$ & $8.06 \pm 1.03^{d}$ & $5.61 \pm 0.57 c$ & 0.000 \\
\hline & $\mathbb{I R}$ & $0.81 \pm 0.08^{a}$ & $6.99 \pm 0.54^{b}$ & $8.47 \pm 0.78^{c}$ & $13.84 \pm 1.31^{d}$ & $5.60 \pm 0.59 e$ & 0.000 \\
\hline & $\mathrm{p}^{\dagger}$ & 1.000 & 1.000 & 0.000 & 0.000 & 1.000 & \\
\hline \multirow{3}{*}{ Day 15} & Non-IR & $0.61 \pm 0.08^{\circ}$ & $5.69 \pm 0.74^{b}$ & $5.54 \pm 0.87^{b}$ & $6.98 \pm 0.52^{c}$ & $4.35 \pm 0.80^{d}$ & 0.000 \\
\hline & $\mathbb{R}$ & $0.60 \pm 0.06^{\circ}$ & $5.68 \pm 0.75^{b}$ & $6.18 \pm 0.54^{b}$ & $8.16 \pm 0.82^{c}$ & $4.19 \pm 0.65^{d}$ & 0.000 \\
\hline & $\mathrm{p}^{\dagger}$ & 1.000 & 1.000 & 0.459 & 0.004 & 1.000 & \\
\hline \multirow{3}{*}{ Day 21} & Non-IR & $0.38 \pm 0.06^{\circ}$ & $4.86 \pm 0.78^{b}$ & $3.34 \pm 0.59 c$ & $4.48 \pm 0.63^{b}$ & $2.43 \pm 0.44^{d}$ & 0.000 \\
\hline & $\mathbb{I R}$ & $0.39 \pm 0.05^{a}$ & $4.81 \pm 0.80^{b}$ & $5.61 \pm 0.57 c$ & $6.88 \pm 0.52^{d}$ & $2.45 \pm 0.43^{e}$ & 0.000 \\
\hline & $\mathrm{p}^{\dagger}$ & 1.000 & 1.000 & 0.000 & 0.000 & 1.000 & \\
\hline \multirow{3}{*}{ Day 28} & Non-IR & $0.21 \pm 0.05^{a}$ & $3.34 \pm 0.59^{b}$ & $1.94 \pm 0.12^{c}$ & $3.04 \pm 0.50^{\mathrm{b}}$ & $1.60 \pm 0.45^{c}$ & 0.000 \\
\hline & $\mathbb{R}$ & $0.21 \pm 0.05^{\circ}$ & $3.39 \pm 0.59 b$ & $3.34 \pm 0.59^{b}$ & $4.58 \pm 0.47 c$ & $1.59 \pm 0.43^{d}$ & 0.000 \\
\hline & $\mathrm{p}^{\dagger}$ & 1.000 & 1.000 & 0.000 & 0.000 & 1.000 & \\
\hline \multirow{3}{*}{ Day 35} & Non-IR & $0.17 \pm 0.07^{\circ}$ & $2.08 \pm 0.28^{b}$ & $1.62 \pm 0.35^{b c}$ & $2.08 \pm 0.28^{b}$ & $1.56 \pm 0.40^{c}$ & 0.000 \\
\hline & $\mathbb{R}$ & $0.17 \pm 0.07^{\circ}$ & $2.09 \pm 0.28^{b}$ & $2.04 \pm 0.37^{b}$ & $2.58 \pm 0.43^{c}$ & $1.54 \pm 0.39^{d}$ & 0.000 \\
\hline & $\mathrm{p}^{\dagger}$ & 1.000 & 1.000 & 0.108 & 0.023 & 1.000 & \\
\hline \multirow{3}{*}{ Day 39} & Non-IR & $0.14 \pm 0.05^{\circ}$ & $1.94 \pm 0.12^{b}$ & $1.46 \pm 0.32^{c}$ & $2.03 \pm 0.29^{b}$ & $1.50 \pm 0.33^{c}$ & 0.000 \\
\hline & $\mathbb{R}$ & $0.13 \pm 0.05^{\circ}$ & $1.95 \pm 0.13^{\mathrm{b}}$ & $1.70 \pm 0.37^{\mathrm{bd}}$ & $2.32 \pm 0.29 c$ & $1.50 \pm 0.33^{d}$ & 0.000 \\
\hline & $\mathrm{p}^{\dagger}$ & 1.000 & 1.000 & 0.465 & 0.277 & 1.000 & \\
\hline
\end{tabular}

Same small letters indicates no statistical difference in the row for each subgroup on the test day. $\mathrm{p}^{\dagger}$ : Significance level between Non-IR and IR groups for each material on the test day. $p^{\ddagger}$ : Significance levels of among the materials in each subgroup at the test day. 
in Zirconomer group after irradiation ( $\mathrm{p}<0.05)$. Some representative AFM images were shown in Figures 1 and 2 . The flexural strength values (MPa) of the materials in the Non-IR and IR subgroups are revealed in Table 4 . The ionizing radiation did not alter the flexural strength values of none of the materials. The highest flexural strength values were obtained from Beautifil II in the Non-IR and IR subgroups $(\mathrm{p}<0.05)$.

A statistically significant positive correlation was observed between surface roughness ( $\mathrm{Ra}$ ) and fluoride release on all the test days $(\mathrm{p}<0.05)$. A statistically significant negative correlation was found between surface roughness and flexural strength (MPa) and between fluoride release and flexural strength on all the test days $(\mathrm{p}<0.05)$. The Pearson's correlation coefficient values are shown in Figure 3.
The representative spectra of EDS analysis are shown in Figure 4. Representative SEM photomicrographs are illustrated in Figures 5 and 6. In EDS analyses, all materials showed a dominance of oxygen, aluminum, and silicon in both the Non-IR and IR subgroups.

\section{Discussion}

The present study was performed to evaluate the effect of ionizing radiation from high energy $\mathrm{X}$-ray on fluoride release, surface roughness, flexural strength, and chemical compositions of the materials' surface. The recommended radiotherapy protocol for head and neck cancer increased the amount of released fluoride and surface roughness of only Amalgomer CR and Zirconomer. Therefore, the null hypothesis, that there

Table 3. Mean and standard deviation values of surface roughness $(\eta \mathrm{m})$ of the materials.

\begin{tabular}{lccc}
\hline Variable & Non-Irradiated & Irradiated & $\mathrm{p}^{\dagger}$ \\
\hline Beautifil II & $55.19 \pm 14.11^{\mathrm{a}}$ & $57.77 \pm 15.61^{\mathrm{a}}$ & 1.000 \\
GCP Glass Fill & $94.32 \pm 21.91^{\mathrm{b}}$ & $107.29 \pm 24.51^{\mathrm{b}}$ & 0.980 \\
Amalgomer CR & $65.36 \pm 16.91^{\mathrm{ab}}$ & $125.33 \pm 28.85^{\mathrm{b}}$ & 0.000 \\
Zirconomer & $87.96 \pm 21.36^{\mathrm{ab}}$ & $168.33 \pm 26.81^{\mathrm{c}}$ & 0.000 \\
Fuji IX GP & $67.37 \pm 18.43^{\mathrm{ab}}$ & $90.67 \pm 21.99^{\mathrm{ab}}$ & 0.587 \\
$\mathrm{p}^{\ddagger}$ & 0.000 & 0.000 & \\
\hline
\end{tabular}

Same small letters indicates no statistical difference in the column. $\mathrm{p}^{\dagger}$ : Significance levels between non-irradiated and irradiated subgroups for each material. $p^{\ddagger}$ : Significance levels among the materials in each subgroup.

A

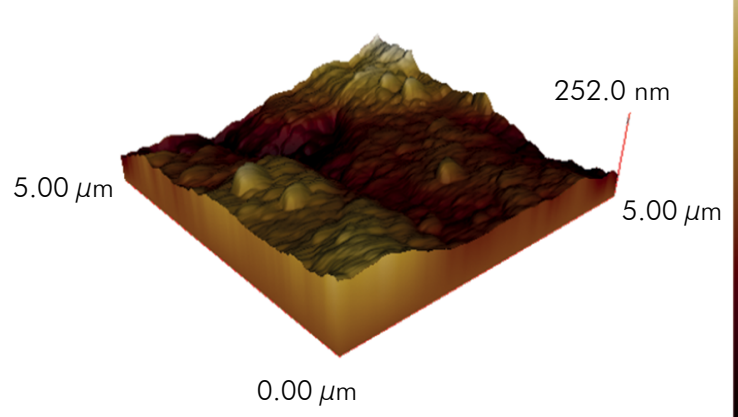

Non-IR

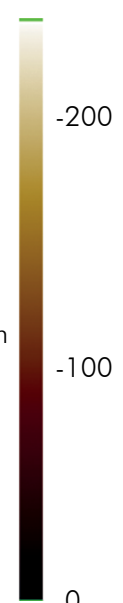

$-0$

$-200$
B

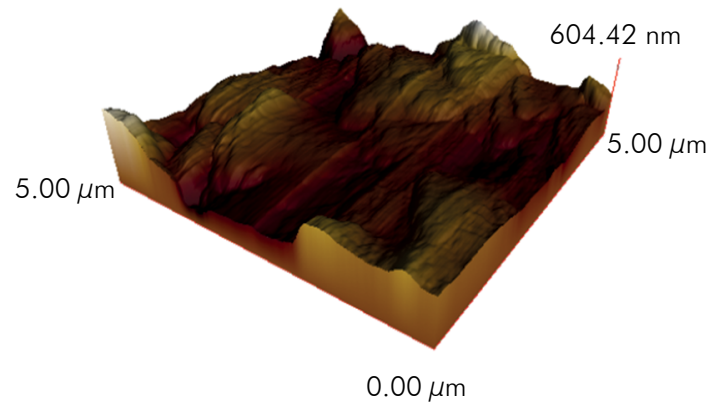

$\mid R$

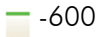

Figure 1. A: AFM image of Amalgomer CR in the Non-IR (non-irradiated) subgroup. The topographical AFM 3D-images were acquired in the contact mode from a $5 \times 5 \mu \mathrm{m}$ area; B: AFM image of Amalgomer CR in the IR (irradiated) subgroup. The topographical AFM 3D-images were acquired in the contact mode from $5 \times 5 \mu \mathrm{m}$ area. 
A

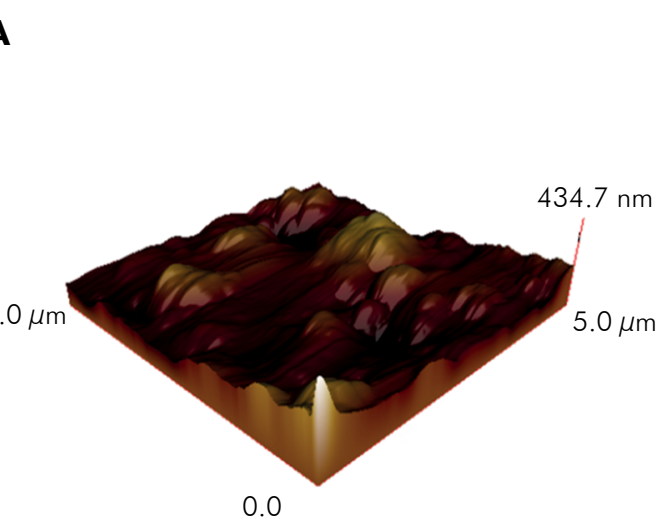

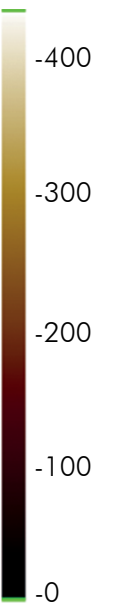

B

Non-IR

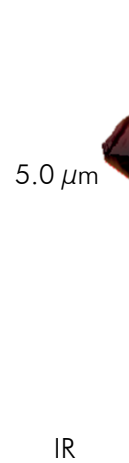

$-600$

$812.5 \mathrm{~nm}$

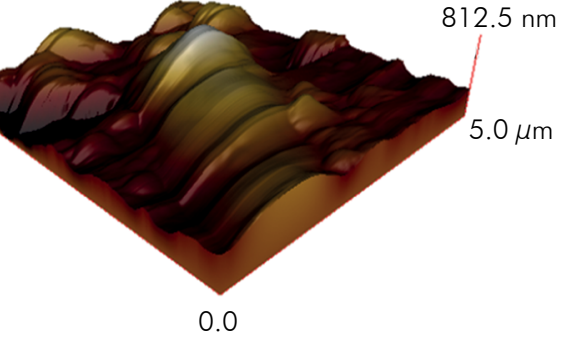

Figure 2. A: AFM image of Zirconomer in the Non-IR (non-irradiated) subgroup. The topographical AFM 3D-images were acquired in the contact mode from $5 \times 5 \mu \mathrm{m}$ area; B: AFM image of Zirconomer in the IR (irradiated) subgroup. The topographical AFM $3 \mathrm{D}$-images were acquired in the contact mode from $5 \times 5 \mu \mathrm{m}$ area.

Table 4. Mean and standard deviation values of flexural strength $(\mathrm{MPa})$ of the materials.

\begin{tabular}{lccc}
\hline Variable & Non-Irradiated & Irradiated & $p^{\dagger}$ \\
\hline Beautifil II & $114.50 \pm 10.58^{a}$ & $114.58 \pm 10.67^{\mathrm{a}}$ & 1.000 \\
GCP Glass Fill & $29.89 \pm 2.31^{\mathrm{b}}$ & $29.87 \pm 2.39^{\mathrm{b}}$ & 1.000 \\
Amalgomer CR & $37.23 \pm 3.73^{\mathrm{bc}}$ & $30.16 \pm 2.12^{\mathrm{b}}$ & 0.126 \\
Zirconomer & $36.47 \pm 2.85^{\mathrm{bc}}$ & $30.16 \pm 2.36^{\mathrm{b}}$ & 0.246 \\
Fujı IX GP & $43.72 \pm 4.29^{\mathrm{c}}$ & $42.70 \pm 3.64^{\mathrm{c}}$ & 1.000 \\
$\mathrm{p}^{\ddagger}$ & 0.000 & 0.000 & \\
\hline
\end{tabular}

Same small letters indicates no statistical difference in the column. $\mathrm{p}^{\dagger}$ : Significance levels between non-irradiated and irradiated subgroups for each material. $p^{\ddagger}$ : Significance levels among materials in each subgroup.

is no significant effect of ionizing radiation from high energy X-ray on the properties of fluoride-releasing restorative materials, was partially rejected.

The use of fluoride-releasing restorative materials has gradually increased because of the inhibitory effects of fluoride on caries ${ }^{5,11,13}$ while several laboratory studies have been also performed to evaluate the amount of fluoride release from the materials. ${ }^{13,14,15,16,27}$ It has been reported that the higher fluoride release of GICs could provide higher antibacterial activity. ${ }^{15,17}$ The fluoride release of restorative materials differs based on various factors such as material type, chemical composition, powder-liquid ratio used during material preparation, mixing method, surface area of material exposed to the environment, storage medium, $\mathrm{pH}$ of the environment or storage medium, surface treatment, and finishing procedures. ${ }^{13,28}$ The ionizing radiation may be one of these factors. But, in the present study, the ionizing radiation significantly increased the amount of fluoride released from only Zirconomer and Amalgomer CR at certain test periods. The amount of fluoride release from Beautifil II was quite low compared to the other materials during all of the test periods. This result is also in agreement with the findings of previous studies. ${ }^{13,16,28}$ It has been reported that the fluoride release capability of Beautifil II was lower than that of glass-ionomer based materials. ${ }^{16,28}$ Beautifil II is a giomer material where S-PRG filler particles are incorporated in the resin matrix. ${ }^{18}$ S-PRG fillers are fabricated by acidbase reactions between the surface of the fluoridated glass filler and poly-acrylic acid in the presence of water. ${ }^{29}$ Giomer materials have no glass ionomer matrix phase, because of the lack of any acid base reaction..$^{13,29}$ They contain only S-PRG particles as a fluoride component, so the amount of fluoride release 


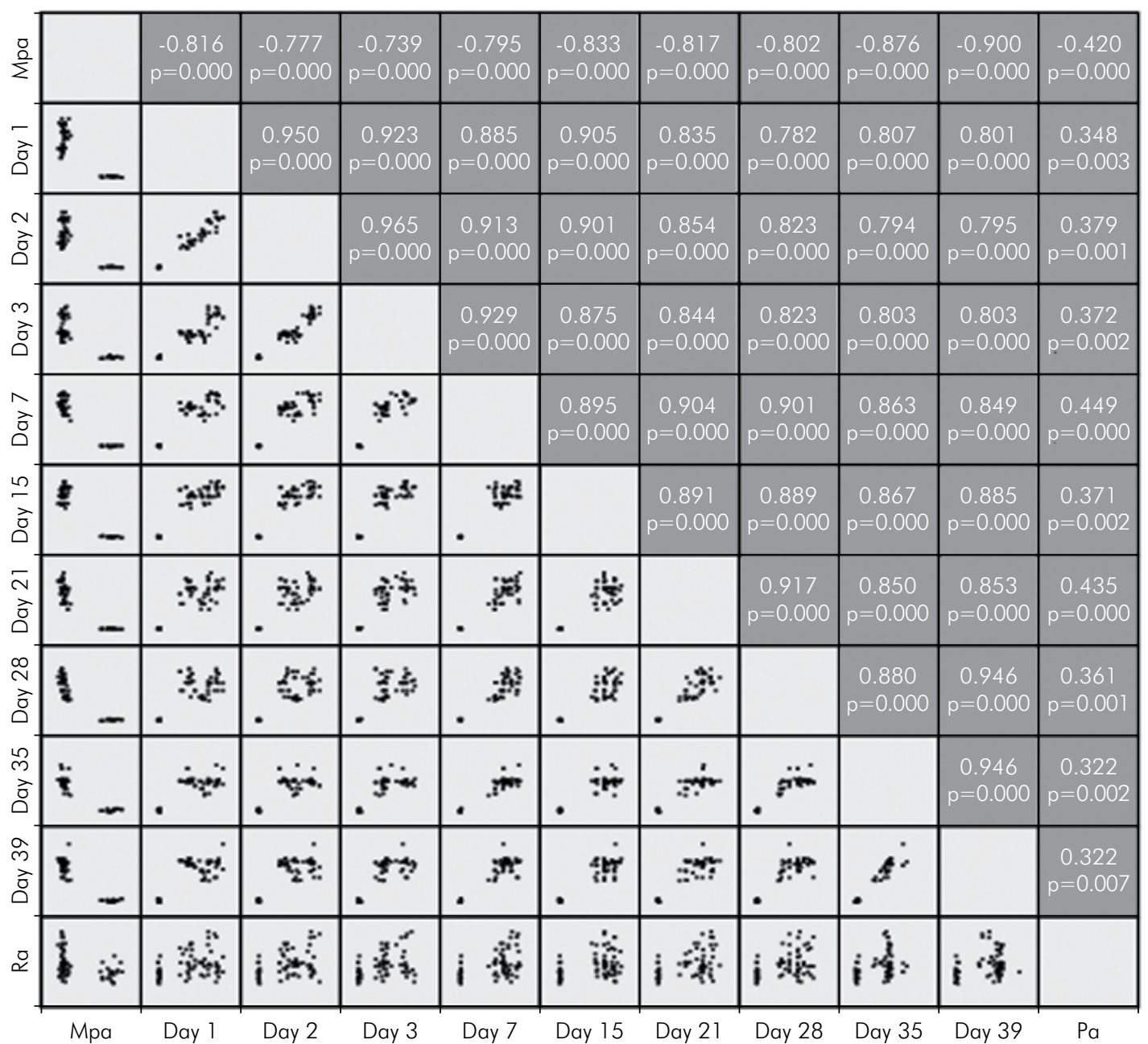

Figure 3. Pearson's correlation coefficient values for the properties of the materials. A statistically significant positive correlation was observed between surface roughness $(\mathrm{Ra})$ and fluoride release $(p<0.05)$. The statistically significant negative correlation was found between surface roughness and flexural strength $(\mathrm{MPa})$, and between fluoride release and flexural strength $(p<0.05)$.

from giomer materials was found to be lower than that of GIC-based materials. ${ }^{16,29}$ Moreover, it has been also stated that the resin in the resin-based materials may act as a diffusion barrier for fluoride and water. ${ }^{29}$ It is well established that GICs show the highest amount of fluoride release on the first day and then it rapidly decreases and stabilizes after three to four weeks. ${ }^{13-16,28}$ This phenomenon is called burst effect, which is the rapid elution of fluoride as a result of the acid base reaction on the glass particle' surface. ${ }^{13}$ In this study, the initial fluoride release of GCP Glass Fill, Amalgomer CR, Zirconomer, and Fuji IX materials occurred as a burst effect, in accordance with previous studies. ${ }^{13,14,15,16,28}$ The highest fluoride release values were observed from Zirconomer in the
Non-IR and IR subgroups on the first day, which may be attributed to its chemical composition as found in previous studies. ${ }^{15,17}$

The fluoride release may provide antibacterial property to the restorative materials. ${ }^{15,16,17}$ However, the antibacterial activity of the materials is not only dependent on released fluoride but also on the metal ions such as aluminum, strontium, zirconium, and barium. ${ }^{30,31}$ It has been reported that composite resin containing zirconium oxide particles and aluminum borate whisker showed higher antibacterial activity. ${ }^{32}$ In this study, antibacterial activity was not evaluated, but it is necessary to conduct further studies to investigate the antibacterial effects of different contents of materials. 


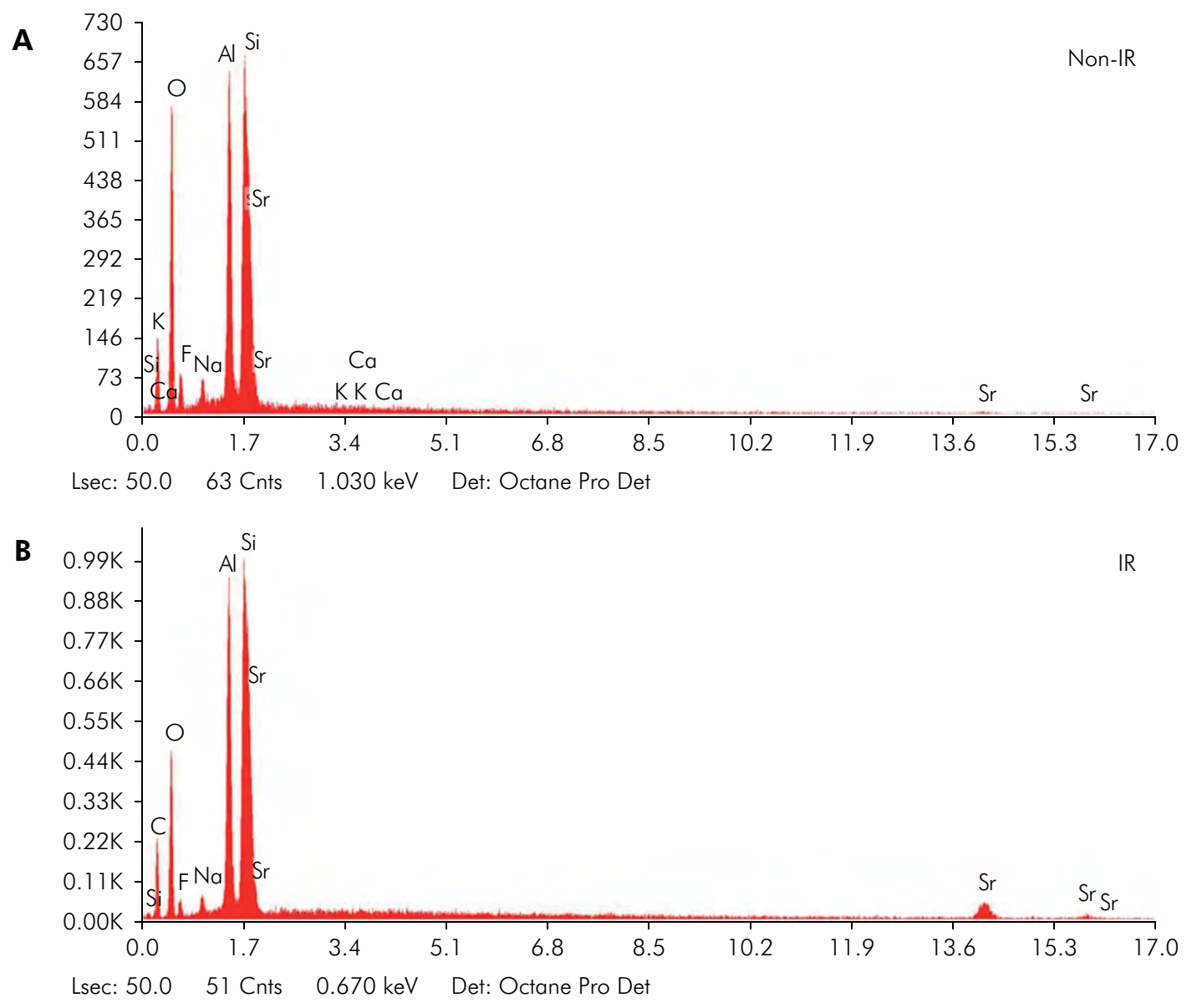

Figure 4. A: EDS spectra acquired from Beautifil II in the Non-IR (non-irradiated) subgroup. All materials showed predominance of oxygen, aluminum, and silicon in both the Non-IR and IR subgroups; B: EDS spectra acquired from Beautifil II in the IR (irradiated) subgroup. All materials showed predominance of oxygen, aluminum and silicon in both the Non-IR and IR subgroups.
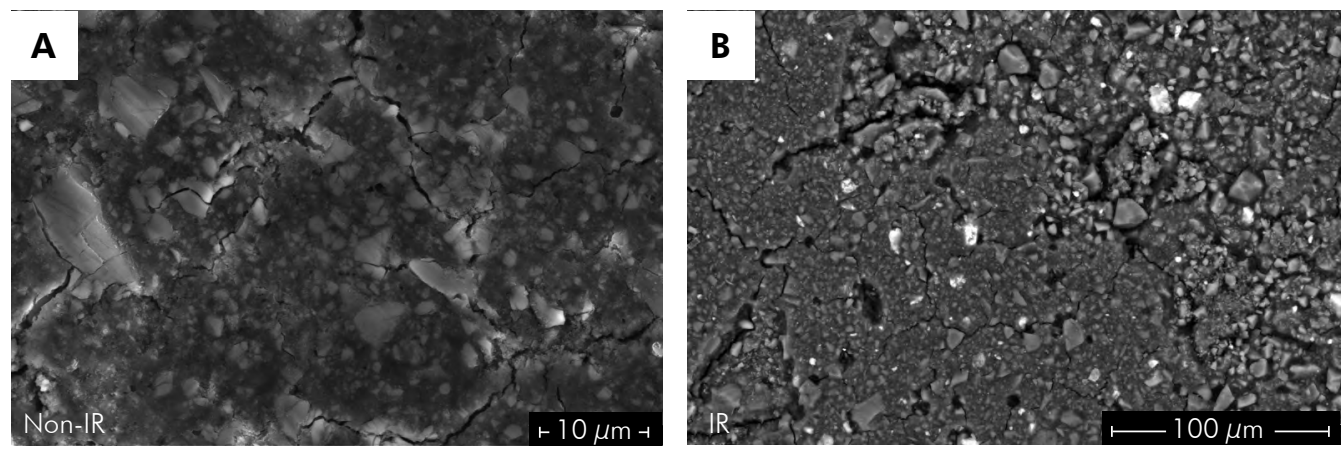

Figure 5. A: SEM photomicrograph of Amalgomer CR in the Non-IR (non-irradiated) subgroup. The photomicrographs were obtained with secondary electrons mode at $15 \mathrm{kV}$. Cracks were observed on the surface of the specimens; B: SEM photomicrograph of Amalgomer CR in the IR (irradiated) subgroup. The photomicrographs were obtained with secondary electrons mode at $15 \mathrm{kV}$. Cracks were observed on the surface of the specimens.

The surface roughness of restorative materials has a major effect on the discoloration and initial bacterial adhesion. ${ }^{33}$ Surface roughness can be measured by quantitative methods, such as profilometry and AFM. 

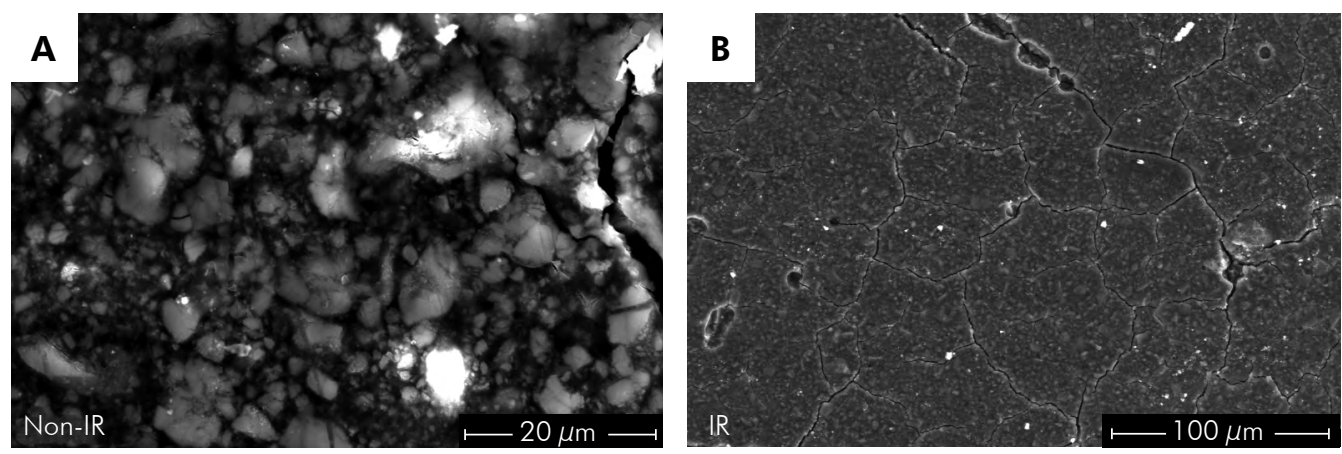

Figure 6. A: SEM photomicrograph of Zirconomer in the Non-IR (non-irradiated) subgroup. The photomicrographs were obtained with secondary electrons mode at $15 \mathrm{kV}$. Cracks were observed on the surface of the specimens; B: SEM photomicrograph of Zirconomer in the IR (irradiated) subgroup. The photomicrographs were obtained with secondary electrons mode at $15 \mathrm{kV}$. Cracks were observed on the surface of the specimens.

AFM has been stated as the most reliable technique in the evaluation of surface roughness. ${ }^{34} \mathrm{AFM}$ provides a topographic image with sub-nanometer resolution by scanning the material surface not requiring working in vacuum and preparation of the specimen. ${ }^{35}$ It has been reported that surface roughness values above $0.2 \mu \mathrm{m}$ increased bacterial adhesion. ${ }^{33}$ In the present study, none of the tested materials showed $\mathrm{Ra} \geq$ $0.2 \mu \mathrm{m}$ in the Non-IR and IR subgroups. The surface roughness values of Amalgomer $\mathrm{CR}$ and Zirconomer showed a significant increase after irradiation, although the irradiation did not affect the surface roughness of Beautifil II, GCP Glass Fill, and Fuji IX GP. In a previous study, ionizing radiation increased the surface roughness of a resin-modified GIC, but it did not affect Ra values of conventional GIC and composite resins..$^{19}$ In another study, the irradiation did not alter the surface roughness of composite resins.$^{20}$ In the present study, similar Ra values were observed from Beautifil II and the glass-ionomer based materials in the Non-IR and IR subgroups. The result is accordance with previous findings in which Beautifil II showed similar surface roughness with glass-ionomer based materials. ${ }^{16}$

In the present study, the ionizing radiation altered fluoride release and surface roughness properties of only Amalgomer CR and Zirconomer. The effect of ionizing radiation on Zirconomer and Amalgomer CR could be due to their chemical compositions. Zirconomer is a reinforced GIC with zirconia fillers. Zirconia $\left(\mathrm{ZrO}_{2}\right)$ is a white crystalline oxide of zirconium, which is polycrystalline ceramic without a glassy phase. ${ }^{15}$ Amalgomer CR is a ceramic-reinforced GIC, which includes a particulate ceramic component. ${ }^{16}$ The ionizing radiation interacts with metallic components, intensifying the radiation in the surroundings of the material. ${ }^{36}$ The intensified radiation can affect the properties of the materials. ${ }^{10,37}$ However, the results are not exactly enough to explain that the increases in fluoride release and surface roughness result from the chemical content of the materials, and future studies are needed.

Flexural strength is one of the significant mechanical properties of dental restorative materials. ${ }^{25}$ The three-point bending test is very popular, and standardized by the International Standards Organization (ISO 4049) for testing polymer-based dental restorative materials. ${ }^{25}$ The flexural strength could alter depending on some factors as hydrolytic degradation from the absorption of water by hydrophilic monomers in restorative materials, unreacted monomers releasing from the material network, and microcracks caused by the rupture of bonds between the filler particles and material matrix. ${ }^{38}$ In the present study, the irradiation protocol did not affect the flexural strength values of the tested materials. In a previous study, it has been reported that irradiation increased flexural strength values of conventional and resin modified GICs. ${ }^{19}$ The authors attributed the results to the additional polymerization resulting from the irradiation. Conversely, clinical studies have reported that the mechanical properties of GIC were severely affected in an indirect way by hyposalivation..$^{5,11}$ It has been also reported that 
irradiation did not affect flexural strength values of composite resins. ${ }^{19,21,23}$ In this study, the highest flexural strength values were observed for Beautifil II in the Non-IR and IR subgroups. The data reported in the present study are in agreement with others that also concluded that giomer restorative materials have significantly higher mechanical properties than the GICs. ${ }^{27,38}$ On the other hand, the main affected regions of the teeth from radiation-related caries are cervical areas. ${ }^{5,6}$ The minimum requirement of ISO 4049 for occlusal restorations is $80 \mathrm{MPa} .{ }^{25}$ The cervical area of the teeth is influenced by flexural forces during function and parafunction. ${ }^{39}$ In addition, cervical deformation could occur when the more rigid composite resins, which have high flexural strength, are used in cervical restorations. ${ }^{39}$

EDS analysis is a reliable technique to identify and quantify major components in the surfaces of materials. ${ }^{15}$ Characterization of the material's chemical components provides understanding of its various physical, biological, chemical, and mechanical properties. However, it has limitations for precise detection of low molecular weight elements such as carbon, hydrogen, and oxygen.$^{40}$ In this study, no significant changes were observed in the main spectra bands of all the materials in the Non-IR and IR subgroups according to EDS analyses. Similar findings were reported in which ionizing radiation did not change the chemical composition of the GICs and composite resins. ${ }^{19}$ Nevertheless, the results of EDS analysis do not show the exact chemical compositions of materials because the analysis is made on the surface of the materials, in a depth of approximately $1 \mu \mathrm{m} \cdot{ }^{15,40}$

The prophylaxis protocol during and after radiotherapy is the most important factor for the reduction of radiation side effects on healthy tissues, teeth, and restorative materials. In radiotherapy patients, to control for plaque accumulation, chlorhexidine mouthwashes should be done in conjunction with and after normal daily toothbrushing with a soft brush; fluoride prophylaxis with custom made carriers should be maintained. In vitro studies do not exactly reflect the actual status of the oral cavity since the oral environment is dynamic and different from laboratory conditions. Laboratory studies simulating most clinical conditions are very useful to assess behavior of biomaterials. The effects of irradiation on the other chemical and mechanical properties of restorative materials should be assessed in further studies. Clinical studies are also needed to evaluate the performance of different restorative materials in irradiated patients. Dentists must be aware of the radiation effects and be careful when choosing a restorative material for irradiated patients.

\section{Conclusion}

Within the limitations of this study, it is possible to conclude that the recommended radiotherapy protocol for head and neck cancer increased the amount of fluoride release and surface roughness of some glass ionomer-based materials. The effect could be related to chemical compositions of the reinforced GICs. However, the irradiation did not influence flexural properties and surface chemical composition of the materials. A positive correlation was observed between surface roughness and fluoride release and a negative correlation between surface roughness and flexural strength and between fluoride release and flexural strength.

\section{Acknowledgments}

The authors thank Shofu Dental, GC Corporation, Dual Dental, and Advanced Healthcare Ltd for providing the materials for this study.

\section{References}

1. De Sanctis V, Bossi P, Sanguineti G, Trippa F, Ferrari D, Bacigalupo A, et al. Mucositis in head and neck cancer patients treated with radiotherapy and systemic therapies: literature review and consensus statements. Crit Rev Oncol Hematol. 2016 Apr;100:147-66. https://doi.org/10.1016/i.critrevonc.2016.01.010

2. Yeh SA. Radiotherapy for head and neck cancer. Semin Plast Surg. 2010 May;24(2):127-36. https://doi.org/10.1055/s-0030-1255330 
The effect of ionizing radiation on properties of fluoride-releasing restorative materials

3. Bichsel D, Lanfranchi M, Attin T, Grätz KW, Stadlinger B. Evaluation of oral prophylaxis during and after intensity-modulated radiotherapy due to head and neck cancer: a retrospective study. Clin Oral Investig. 2016 May;20(4):721 -4. https://doi.org/10.1007/s00784-015-1546-9

4. Devi S, Singh N. Dental care during and after radiotherapy in head and neck cancer. Natl J Maxillofac Surg. 2014 Jul-Dec;5(2):117-25. https://doi.org/10.4103/0975-5950.154812

5. De Moor RJ, Stassen IG, van ' $\nmid$ Veldt Y, Torbeyns D, Hommez GM. Two-year clinical performance of glass ionomer and resin composite restorations in xerostomic head- and neck-irradiated cancer patients. Clin Oral Investig. 2011 Feb;15(1):31-8. https://doi.org/10.1007/s00784-009-0355-4

6. Gupta N, Pal M, Rawat S, Grewal MS, Garg H, Chauhan D, et al. Radiation-induced dental caries, prevention and treatment: a systematic review. Natl J Maxillofac Surg. 2015 Jul-Dec;6(2):160-6. https://doi.org/10.4103/0975-5950.183870

7. Silva AR, Alves FA, Berger SB, Giannini M, Goes MF, Lopes MA. Radiation-related caries and early restoration failure in head and neck cancer patients: a polarized light microscopy and scanning electron microscopy study. Support Care Cancer. 2010 Jan;18(1):83-7. https://doi.org/10.1007/s00520-009-0633-3

8. Gonçalves LM, Palma-Dibb RG, Paula-Silva FW, Oliveira HF, Nelson-Filho P, Silva LA, et al. Radiation therapy alters microhardness and microstructure of enamel and dentin of permanent human teeth. J Dent. 2014 Aug;42(8):986-92. https://doi.org/10.1016/j.jdent.2014.05.011

9. Lieshout HF, Bots CP. The effect of radiotherapy on dental hard tissue--a systematic review. Clin Oral Investig. 2014 Jan;18(1):17-24. https://doi.org/10.1007/s00784-013-1034-z

10. Madrid Troconis CC, Santos-Silva AR, Brandão TB, Lopes MA, Goes MF. Impact of head and neck radiotherapy on the mechanical behavior of composite resins and adhesive systems: a systematic review. Dent Mater. 2017 Nov;33(11):1229-1243. https://doi.org/10.1016/i.dental.2017.07.014

11. McComb D, Erickson RL, Maxymiw WG, Wood RE. A clinical comparison of glass ionomer, resin-modified glass ionomer and resin composite restorations in the treatment of cervical caries in xerostomic head and neck radiation patients. Oper Dent. 2002 Sep-Oct;27(5):430-7.

12. Haveman CW, Summitt JB, Burgess JO, Carlson K. Three restorative materials and topical fluoride gel used in xerostomic patients: a clinical comparison. J Am Dent Assoc. 2003 Feb;134(2):177-84. https://doi.org/10.14219/jada.archive.2003.0131

13. Garoushi S, Vallittu PK, Lassila L. Characterization of fluoride releasing restorative dental materials. Dent Mater J. 2018 Mar;37(2):293-300. https://doi.org/10.4012/dmi.2017-161

14. Shiozawa M, Takahashi H, Iwasaki N. Fluoride release and mechanical properties after 1-year water storage of recent restorative glass ionomer cements. Clin Oral Investig. 2014 May;18(4):1053-60. https://doi.org/10.1007/s00784-013-1074-4

15. Saxena S, Tiwari S. Energy dispersive X-ray microanalysis, fluoride release, and antimicrobial properties of glass ionomer cements indicated for atraumatic restorative treatment. J Int Soc Prev Community Dent. 2016 Jul-Aug;6(4):366-72. https://doi.org/10.4103/2231-0762.186790

16. Bayrak GD, Sandalli N, Selvi-Kuvvetli S, Topcuoglu N, Kulekci G. Effect of two different polishing systems on fluoride release, surface roughness and bacterial adhesion of newly developed restorative materials. J Esthet Restor Dent. 2017 Nov;29(6):424-34. https://doi.org/10.1111/jerd.12313

17. Tiwari S, Kenchappa M, Bhayya D, Gupta S, Saxena S, Satyarth S, et al. Antibacterial Activity and Fluoride Release of Glass-lonomer Cement, Compomer and Zirconia Reinforced Glass-lonomer Cement. J Clin Diagn Res. 2016 Apr;10(4):ZC90-3. https://doi.org/10.7860/JCDR/2016/16282.7676

18. Tay FR, Pashley EL, Huang C, Hashimoto M, Sano H, Smales RJ, et al. The glass-ionomer phase in resin-based restorative materials. J Dent Res. 2001 Sep;80(9):1808-12. https://doi.org/10.1177/00220345010800090701

19. Brandeburski SB, Della Bona A. Effect of ionizing radiation on properties of restorative materials. Dent Mater. 2018 Feb;34(2):221-7. https://doi.org/10.1016/j.dental.2017.10.006

20. Viero FL, Boscolo FN, Demarco FF, Faot F. Effect of radiotherapy on the hardness and surface roughness of two composite resins. Gen Dent. 2011 Jul-Aug;59(4):e168-72.

21. Catelan A, Padilha AC, Salzedas LM, Coclete GA, Santos PH. Effect of radiotherapy on the radiopacity and flexural strength of a composite resin. Acta Odontol Latinoam. 2008;21(2):159-62.

22. Haque S, Takinami S, Watari F, Khan MH, Nakamura M. Radiation effects of carbon ions and gamma ray on UDMA based dental resin. Dent Mater J. 2001 Dec;20(4):325-38. https://doi.org/10.4012/dmi.20.325

23. Fraunhofer JA, Curtis P Jr, Sharma S, Farman AG. The effects of gamma radiation on the properties of composite restorative resins. J Dent. 1989 Aug;17(4):177-83. https://doi.org/10.1016/0300-5712(89)90071-7

24. Hahnel S, lonescu AC, Cazzaniga G, Ottobelli M, Brambilla E. Biofilm formation and release of fluoride from dental restorative materials in relation to their surface properties. J Dent. 2017 May;60:14-24. https://doi.org/10.1016/j.jdent.2017.02.005

25. Janda R, Roulet JF, Latta M, Rüttermann S. The effects of thermocycling on the flexural strength and flexural modulus of modern resin-based filling materials. Dent Mater. 2006 Dec;22(12):1103-8. https://doi.org/10.1016/j.dental.2005.09.005

26. Xie D, Brantley WA, Culbertson BM, Wang G. Mechanical properties and microstructures of glass-ionomer cements. Dent Mater. 2000 Mar;16(2):129-38. https://doi.org/10.1016/S0109-5641(99)00093-7

27. Naoum S, Ellakwa A, Martin F, Swain M. Fluoride release, recharge and mechanical property stability of various fluoride-containing resin composites. Oper Dent. 2011 Jul-Aug;36(4):422-32. https://doi.org/10.2341/10-414-L 
28. Jingarwar MM, Pathak A, Bajwa NK, Sidhu HS. Quantitative assessment of fluoride release and recharge ability of different restorative materials in different media: an in vitro study. J Clin Diagn Res. 2014 Dec;8(12):ZC31-4. https://doi.org/10.7860/JCDR/2014/9985.5275 P

29. Mousavinasab SM, Meyers I. Fluoride release by glass ionomer cements, compomer and giomer. Dent Res J (Isfahan). 2009;6(2):75-81.

30. Saku S, Kotake H, Scougall-Vilchis RJ, Ohashi S, Hotta M, Horiuchi S, et al. Antibacterial activity of composite resin with glass-ionomer filler particles. Dent Mater J. 2010 Mar;29(2):193-8. https://doi.org/10.4012/dmi.2009-050

31. Hotwani K, Thosar N, Baliga S, Bundale S, Sharma K. Antibacterial effects of hybrid tooth colored restorative materials against Streptococcus mutans: an in vitro analysis. J Conserv Dent. 2013 Jul;16(4):319-22. https://doi.org/10.4103/0972-0707.114358

32. Chen R, Han Z, Huang Z, Karki J, Wang C, Zhu B, et al. Antibacterial activity, cytotoxicity and mechanical behavior of nano-enhanced denture base resin with different kinds of inorganic antibacterial agents. Dent Mater J. 2017 Nov 29;36(6):693-699. https://doi.org/10.4012/dmj.2016-301

33. Hahnel S, lonescu AC, Cazzaniga G, Ottobelli M, Brambilla E. Biofilm formation and release of fluoride from dental restorative materials in relation to their surface properties. J Dent. 2017 May;60:14-24. https://doi.org/10.1016/j.jdent.2017.02.005

34. Kakaboura A, Fragouli M, Rahiotis C, Silikas N. Evaluation of surface characteristics of dental composites using profilometry, scanning electron, atomic force microscopy and gloss-meter. J Mater Sci Mater Med. 2007 Jan;18(1):155-63. https://doi.org/10.1007/s10856-006-0675-8

35. Giacomelli L, Derchi G, Frustaci A, Orlando B, Covani U, Barone A, et al. Surface roughness of commercial composites after different polishing protocols: an analysis with atomic force microscopy. Open Dent J. 2010 Sep;4(1):191-4. https://doi.org/10.2174/1874210601004010191

36. Cruz A, Sinhoreti M, Ambrosano G, Rastelli A, Bagnato V, Bóscolo F. Effect of therapeutic dose X rays on mechanical and chemical properties of esthetic dental materials. Mater Res. 2008;11(3):313-8. https://doi.org/10.1590/S1516-14392008000300014

37. Chin DW, Treister N, Friedland B, Cormack RA, Tishler RB, Makrigiorgos GM, et al. Effect of dental restorations and prostheses on radiotherapy dose distribution: a Monte Carlo study. J Appl Clin Med Phys. 2009 Feb;10(1):2853. https://doi.org/10.1120/jacmp.v10i1.2853

38. Zhou X, Wang S, Peng X, Hu Y, Ren B, Li M, et al. Effects of water and microbial-based aging on the performance of three dental restorative materials. J Mech Behav Biomed Mater. 2018 Apr;80:42-50. https://doi.org/10.1016/i.jmbbm.2018.01.023

39. Yap AU, Teoh SH. Comparison of flexural properties of composite restoratives using the ISO and mini-flexural tests. J Oral Rehabil. 2003 Feb;30(2):171-7. https://doi.org/10.1046/j.1365-2842.2003.01004.x

40. Guedes OA, Borges AH, Bandeca MC, Nakatani MK, Estrela CRA, Alencar AH, et al. Chemical and structural characterization of glass ionomer cements indicated for atraumatic restorative treatment. J Contemp Dent Pract. 2015 Jan;16(1):61-7. https://doi.org/10.5005/ip-journals-10024-1636 